\title{
Radiomic Model Predicts Lymph Node Response to Induction Chemotherapy in Locally Advanced Head and Neck Cancer
}

\author{
Michael H. Zhang ${ }^{1}$, David Cao ${ }^{2}$ and Daniel T. Ginat ${ }^{3, *}$ \\ 1 Department of Medicine, The University of Chicago, Chicago, IL 60637, USA; Michael.Zhang@uchospitals.edu \\ 2 Pritzker School of Medicine, The University of Chicago, Chicago, IL 60637, USA; David.Cao@uchospitals.edu \\ 3 Department of Radiology, The University of Chicago, Chicago, IL 60637, USA \\ * Correspondence: dtg1@uchicago.edu; Tel.: +1-773-702-6039
}

Citation: Zhang, M.H.; Cao, D.; Ginat, D.T. Radiomic Model Predicts Lymph Node Response to Induction Chemotherapy in Locally Advanced Head and Neck Cancer. Diagnostics 2021, 11, 588. https://doi.org/ 10.3390/diagnostics11040588

Academic Editor:

Gustavo Baldassarre

Received: 10 March 2021

Accepted: 22 March 2021

Published: 25 March 2021

Publisher's Note: MDPI stays neutral with regard to jurisdictional claims in published maps and institutional affiliations.

\begin{abstract}
This study developed a pretreatment CT-based radiomic model of lymph node response to induction chemotherapy in locally advanced head and neck squamous cell carcinoma (HNSCC) patients. This was a single-center retrospective study of patients with locally advanced HPV+ HNSCC. Forty-one enlarged lymph nodes were found from 27 patients on pretreatment $\mathrm{CT}$ and were split into 3:1 training and testing cohorts. Ninety-three radiomic features were extracted. A radiomic model and a combined radiomic-clinical model predicting lymph node response to induction chemotherapy were developed using multivariable logistic regression. Median age was 57 years old, and $93 \%$ of patients were male. Post-treatment evaluation was 32 days after treatment, with a median reduction in lymph node volume of $66 \%$. A three-feature radiomic model (minimum, skewness, and low gray level run emphasis) and a combined radiomic-clinical model were developed. The combined model performed the best, with $\mathrm{AUC}=0.85$ on the training cohort and $\mathrm{AUC}=0.75$ on the testing cohort. A pretreatment CT-based lymph node radiomic signature combined with clinical parameters was able to predict nodal response to induction chemotherapy for patients with locally advanced HNSCC.
\end{abstract}

Keywords: radiomics; texture analysis; HNSCC; lymph node; CT; induction chemotherapy; cancer; nodal response

\section{Introduction}

Head and neck squamous cell carcinoma (HNSCC) is a common malignancy with more than 800,000 new cases diagnosed every year globally, the majority of them presenting with locally advanced disease at the time of diagnosis [1]. Patients with locally advanced disease are typically treated with a combination of surgery, radiation, and chemotherapy, but response to clinical treatment varies immensely among patients and outcomes have remained relatively stagnant and unsatisfactory over the past decade [1-3]. In HNSCC, nodal disease remains the most important marker of prognosis; the presence of lymph node metastasis is the most accurate predictor of cancer-related outcomes, and extracapsular spread in metastatic lymph nodes is associated with another drop in overall survival [4-6]. A few other prognostic biomarkers have been validated, namely, human papillomavirus (HPV) status, PD-L1 status, and 18F-fluorodeoxyglucose (FDG) uptake on PET imaging [7-10]. Because of the remarkably heterogenous responses to treatment, there is a need for better prognostic biomarkers to identify those who will and will not respond to treatment and to further personalize treatment regimens.

Radiomics, the field of quantifying image intensity, shape, and textural characteristics through the use of high-throughput data-characterization algorithms, has been proposed as a non-invasive and accessible method to analyze tumors. Radiomic models have previously been studied in a multitude of tumors, across virtually every imaging modality [11-14]. In the realm of HNSCC, radiomics has been utilized to differentiate malignant from benign tissue, to assess HPV status, and to identify underlying driver mutations [15-17]. Other 
studies have used radiomic signatures as prognostic biomarkers and even to predict side effects of treatment such as xerostomia or weight loss [18-21].

There is a need for better predictors of response to HNSCC treatment. Given the importance of nodal disease to the overall prognosis of HNSCC, this study aims to develop a CT-based radiomic biomarker to predict lymph node response to induction chemotherapy in patients with locally advanced HNSCC [22].

\section{Materials and Methods}

\subsection{Patient Population and Treatment}

This retrospective study was approved by the institutional review board at the University of Chicago, and informed consent was waived. A retrospective review of patients with pathology-proven stage IVa or IVb HNSCC, enrolled in a response-adapted volume de-escalation trial between May 2010 and March 2014 at our institution, was included in this study [23]. Patients were 18 years of age or older with Karnofsky performance status of $\geq 70 \%$ and normal organ and marrow function. Patients were excluded if they had HPV-negative HNSCC, if they did not have pretreatment contrast-enhanced CT imaging available for radiomic analysis, or if no enlarged lymph nodes were seen on pretreatment imaging (defined as short axis diameter $>15 \mathrm{~mm}$ ). Patients with prior radiotherapy or chemotherapy, symptomatic peripheral neuropathy, current immunosuppressive therapy, or metastatic disease were excluded. Ultimately, 41 lymph nodes from 27 patients were included.

All patients underwent two 21-day cycles of an induction chemotherapy regimen of cisplatin, paclitaxel, and escalating doses of cetuximab and everolimus. Post-treatment crosssectional evaluation of individual lymph node response was performed approximately 1 month after the induction regimen (median time interval 31 days, range 29-38 days). Volume response was measured as a percent change between the pretreatment and posttreatment lymph node volume.

\subsection{CT Image Acquisition}

Head and neck CT scans were acquired after intravenous injection of typically 50 to $65 \mathrm{~mL}$ of nonionic iodinated contrast medium ( $350 \mathrm{mg}$ of iodine per milliliter, Omnipaque) at a rate of $1.2 \mathrm{~mL} / \mathrm{s}$ and 55 second delay after the start of the injection. The scan parameters included $120 \mathrm{kV}$; $250 \mathrm{mAs}$; rotation time, 1.0 second; pitch, 0.75 ; collimation, $24 \times 1.2 \mathrm{~mm}^{2}$ with a B30s smoothing algorithm, section thicknesses of $3 \mathrm{~mm}$, and display field of view of 20 to $25 \mathrm{~cm}$.

\subsection{CT Texture Analysis}

Pretreatment CT images were analyzed using 3D Slicer 4.10.2 [24]. The axial slice with the largest lymph node cross-sectional area assessed by visual estimation was selected for segmentation. Region of interest (ROI) segmentation was manually performed for each identified lymph node under the supervision of a board-certified neuroradiologist (Figure 1). Ninety-three texture features from 6 classes-first-order features, gray level co-occurrence matrix (GLCM) features, gray level size zone matrix (GLSZM) features, gray level run length matrix (GLRLM) features, neighboring gray tone difference matrix (NGTDM) features, and gray level dependence matrix (GLDM) features-were calculated from each ROI using the Slicer pyradiomics module, which is compliant with the Imaging Biomarker Standardisation Initiative $[25,26]$. These 6 classes and 93 features are described in Supplemental S1.

\subsection{Radiomic Feature Selection}

A radiomic model was developed to logistically predict how lymph nodes would respond to induction chemotherapy. The median reduction in lymph node volume of $66 \%$ was used as the cutoff between good response (GR) and poor response (PR) (Figure S1). 
GR was defined as $>66 \%$ reduction in the target lymph node. Patients with $\leq 66 \%$ decrease in the sum of target lesions were classified as PR.

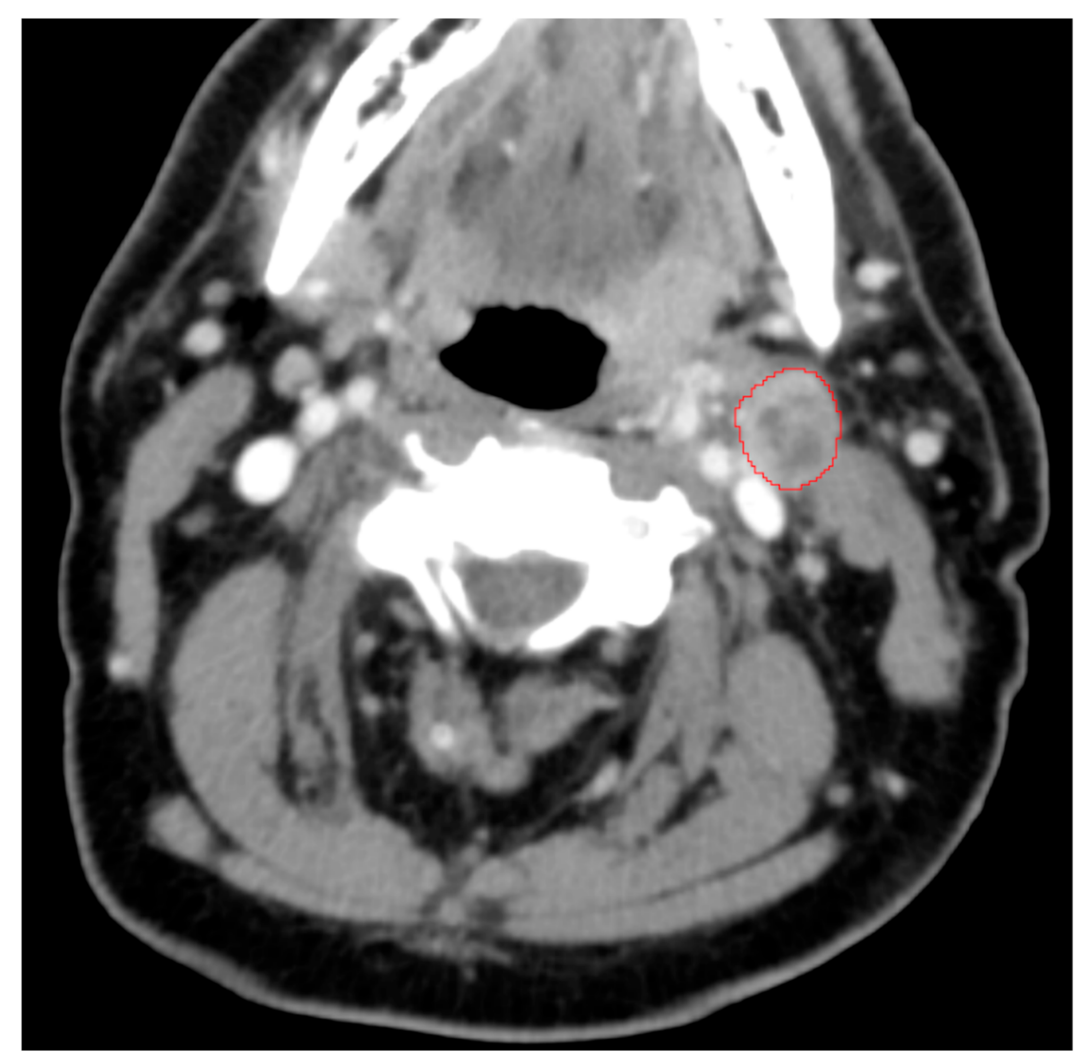

Figure 1. An enlarged lymph node and region of interest outlined on a pretreatment axial CT image.

We started by splitting the dataset of 41 lymph nodes into a training cohort $(n=30)$ and testing cohort $(n=11)$. The feature selection process and radiomic model development were done exclusively on the training cohort. All 93 features were linearly regressed against the percent reduction in lymph node volume. Features with $p \geq 0.05$ after adjustment by the false discovery rate (FDR) were considered statistically insignificant and removed. Next, the radiomic features were assessed for collinearity to avoid redundancy in the model. Any feature that was highly correlated with another feature, defined as a Pearson correlation coefficient $\left|R^{2}\right|>0.8$, was removed. Lastly, a least absolute shrinkage and selection operator (LASSO) regression was applied to identify the most useful and prognostic features while simultaneously eliminating nonpredictive features. The optimal LASSO regularization parameter $\lambda$ was determined by a 5 -fold cross-validation. After the feature selection process, we were left with three radiomic features: minimum, skewness, and low gray level run emphasis (LGRE).

\subsection{Radiomic Model Construction and Evaluation}

A multivariable logistic regression model was performed on the training cohort. This model was then evaluated on the testing cohort. A clinical model (patient age, sex, and TMN staging) was developed on the training cohort for comparison. Lastly, a model combining the radiomic model and clinical features was developed. In the combined model, all the clinical parameters in addition to a predictive Rad-score (which ranged from 0 to 1 with a greater Rad-score predicting higher likelihood of GR) was used. Associated receiver operating characteristic (ROC) curves were plotted for all three models. All statistical analyses were performed with R, Version 4.0.3 (www.r-project.org, accessed on 12 October 2020, Vienna Austria). 


\section{Results}

\subsection{Demographic and Clinical Characteristics}

We retrospectively analyzed 41 lymph nodes from 27 patients with locally advanced HNSCC who were treated between 2010 and 2014 (Table 1). The median patient age of our study population was 57 years old, and 93\% were male. At a median follow-up of 32 days, the median reduction in lymph node volume was $66 \%$. There were no significant differences in the clinical characteristics of our training and testing populations besides the $\mathrm{T}$ stage. Overall stage and $\mathrm{N}$ stage were not significantly different between our cohorts.

Table 1. Clinical characteristics of the patient population.

\begin{tabular}{|c|c|c|c|c|}
\hline & All Subjects & Training Cohort & Testing Cohort & $p$-Value \\
\hline$n$ & 41 & 30 & 11 & \\
\hline Age (years) & $57 \pm 6$ & $58 \pm 7$ & $56 \pm 3$ & 0.57 \\
\hline \multicolumn{5}{|l|}{ Sex } \\
\hline Female & 3 & 3 & 0 & 0.68 \\
\hline Male & 38 & 27 & 11 & \\
\hline Time Interval (days) & $32 \pm 3$ & $32 \pm 3$ & $33 \pm 3$ & 0.48 \\
\hline Lymph Node Reduction (\%) & $66 \%[53-82 \%]$ & $77 \%[53-82 \%]$ & $62 \%[58-67 \%]$ & 0.34 \\
\hline Lymph Node Response & & & & 0.19 \\
\hline Good Response (> 66\%) & 20 & 17 & 3 & \\
\hline Poor Response $(\leq 66 \%)$ & 21 & 13 & 8 & \\
\hline Overall Stage & & & & 0.95 \\
\hline IVa & 39 & 28 & 11 & \\
\hline $\mathrm{IVb}$ & 2 & 2 & 0 & \\
\hline T Stage & & & & 0.04 \\
\hline 1 & 6 & 5 & 1 & \\
\hline 2 & 15 & 7 & 8 & \\
\hline 3 & 11 & 10 & 1 & \\
\hline 4 & 9 & 8 & 1 & \\
\hline N Stage & & & & 0.75 \\
\hline $2 a$ & 2 & 1 & 1 & \\
\hline $2 b$ & 20 & 14 & 6 & \\
\hline $2 c$ & 18 & 14 & 4 & \\
\hline 3 & 1 & 1 & 0 & \\
\hline
\end{tabular}

Time interval is the number of days between the pretreatment scan and follow-up scan. Change in lymph node volume was assessed at this time. Lymph node reduction is the percent change in volume of the lymph node between the pretreatment and follow-up scan. Numerical data are mean \pm standard deviation or median [interquartile range].

\subsection{Radiomic Feature Selection}

We extracted 93 radiomic features from pretreatment contrast-enhanced CT images (Supplemental S1). Each feature was linearly regressed against the percent change in lymph node volume. Of the 93 features, 65 had a statistically significant regression with FDR-adjusted $p$-value $<0.05$ (Table S1 Supplementary Materials). Next, these 65 features were examined for collinearity. Highly colinear variables were removed, and 14 radiomic features remained. A LASSO regression was then performed to eliminate nonsignificant features (Figure S1). A logistic regression model using two first-order features (minimum, skewness) and one gray level run length matrix feature (LGRE) was produced (Table 2). Descriptions of these features can be found in Supplemental S1. Minimum pixel intensity and low gray level run emphasis were positively associated with good lymph node response, while skewness was associated with poorer lymph node response. 
Table 2. Logistic regression model of radiomic features to predict good lymph node response.

\begin{tabular}{cccc}
\hline & Correlation Coefficient & Beta Coefficient \pm SE & $p$ Value \\
\hline (Intercept) & & $-1.26 \pm 1.09$ & 0.25 \\
Minimum & 0.0045 & $0.014 \pm 0.015$ & 0.35 \\
Skewness & -0.083 & $-0.49 \pm 0.39$ & 0.21 \\
Low Gray Level Run & 1.20 & $9.89 \pm 7.11$ & 0.16 \\
Emphasis & & & \\
\hline
\end{tabular}

Good response is $>66 \%$ and poor response is $\leq 66 \%$ reduction in lymph node volume. Correlation coefficient is the relationship between feature value and percent reduction in lymph node volume. Positive value indicates increase in feature value is correlated with greater percent reduction in lymph node volume. SE = standard error.

\subsection{Evaluation of Radiomic and Clinical Models}

The radiomic model was compared with a clinical model (comprised of age, sex, $\mathrm{T}$ stage, and $\mathrm{N}$ stage) and a combined radiomic-clinical model (comprised of Rad-score, age, sex, $\mathrm{T}$ stage, and $\mathrm{N}$ stage). All three models were developed on the training cohort and then validated on the testing cohort. On the training cohort, the combined model did the best $(\mathrm{AUC}=0.85)$, followed by the radiomic $(\mathrm{AUC}=0.76)$ and then clinical model (AUC $=0.73$ ) (Figure 2$)$. In the testing cohort, the combined model $(\mathrm{AUC}=0.75)$ outperformed the radiomic (AUC $=0.67$ ) and clinical models (AUC $=0.62)$ (Figure 3$)$. The combined model was $71 \%$ sensitive and $92 \%$ specific in our training cohort (Table 3 ). In our testing cohort, the model was $100 \%$ sensitive and $50 \%$ specific (Table 4 ).

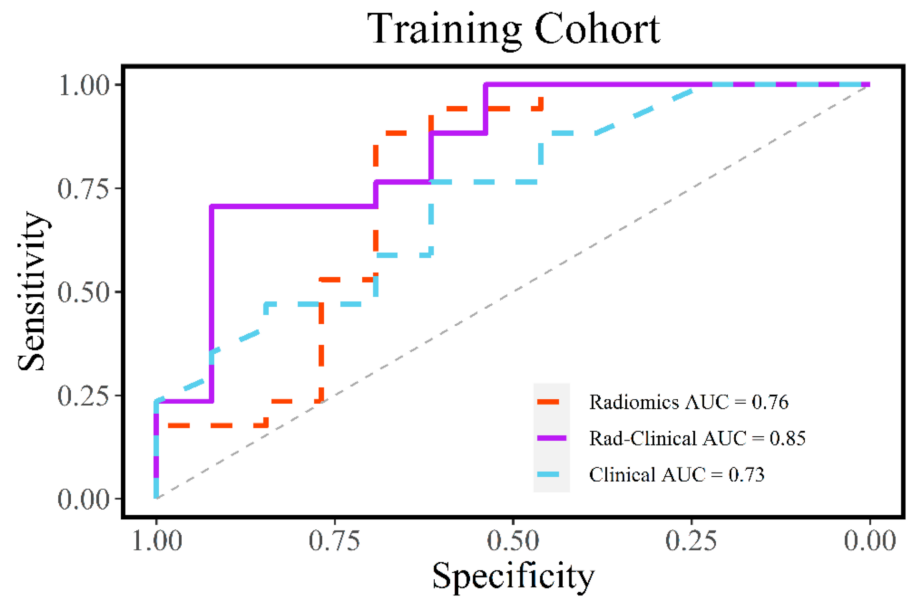

Figure 2. Receiver operating characteristic (ROC) curve analysis for the radiomic, clinical, and combined models in the training cohort. The combined model performed the best.

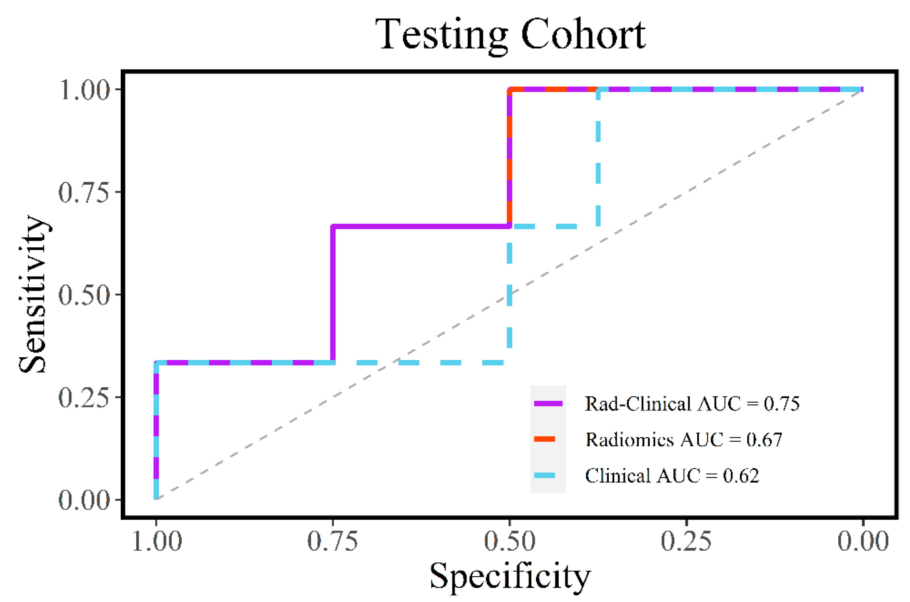

Figure 3. Receiver operating characteristic (ROC) curve analysis for the radiomic, clinical, and combined models in the testing cohort. The combined model performed the best. 
Table 3. Confusion matrix showing the combined radiomic-clinical model performance in the training cohort.

\begin{tabular}{lccc}
\hline & Predicted: Good Response & Predicted: Poor Response \\
\hline Observed: good response & 12 & 5 & 17 \\
Observed: poor response & 1 & 12 & 13 \\
& 13 & 17 & \\
\hline$n=30$. Positive predictive value $92 \%$. Negative predictive value $71 \%$. Sensitivity $71 \%$. Specificity $92 \%$.
\end{tabular}

Table 4. Confusion matrix showing the combined radiomic-clinical model performance in the testing cohort.

\begin{tabular}{lccc}
\hline & Predicted: Good Response & Predicted: Poor Response & \\
\hline Observed: good response & 3 & 0 & 3 \\
Observed: poor response & 4 & 4 & 8 \\
& 7 & 4 & \\
\hline$n=11$. Positive predictive value $43 \%$ Negative predictive value $100 \%$ Sensitivity $100 \%$. Specificity $50 \%$
\end{tabular}

\section{Discussion}

Recent advances in the field of radiomics have allowed for the extraction of informative imaging features to help quantify differences in tumors as seen on imaging. CT-based radiomic features have been used to predict HPV status and extranodal metastasis [27-29]. Radiomic signatures have been used to evaluate intratumoral heterogeneity, something that is difficult to do by tissue biopsy, and were found to be associated with different gene-expression patterns [30,31]. However, there has been minimal work done evaluating individual lymph nodes prior to oncologic treatment. The eighth edition of the pathological tumor-node-metastasis staging classification uses the number, size, and laterality of metastatic lymph nodes and incorporates two new parameters: depth of invasion and extranodal extension [32,33]. Other approaches have used the lymph node ratio (defined as the proportion of metastatic lymph nodes related to all examined nodes) to predict prognosis [34]. León et al. included weighted lymph node ratios to further adjust prognosis for the presence of each node with extracapsular spread [35]. There appears to be prognostic value in the attributes of each individual lymph node. This study is, to our knowledge, the first to develop a radiomic-based model to predict lymph node response after induction chemotherapy.

In this study, we extracted and analyzed 93 radiomic features characterizing enlarged lymph nodes in patients with HNSCC. We developed a logistic regression classifier using three extracted radiomic features. The features utilized in our radiomic model include two first-order features (minimum and skewness) as well as LGRE. Lower minimum voxel intensity predicted poor nodal response to treatment. The minimum attenuation was -5 Hounsfield units (HU) among PR nodes and 18 HU among GR nodes, likely characterizing the low attenuating nature of necrotic lymph nodes. Likewise, LGRE measures the concentration of low attenuating voxels in the ROI. A higher LGRE value (representing a greater concentration of low gray-level values) predicted worse nodal response. Skewness has been used to characterize intratumoral heterogeneity [36-38]. Chen et al. used skewness and minimum in a four-feature signature to classify lung nodules as benign or malignant on CT imaging [39]. It has been previously hypothesized that tumor heterogeneity manifests at different spatial scales, from the macroscopic down to the cellular and genetic level $[31,40,41]$. It is unsurprising that the features elicited in our model to predict lymph node response represent radiologic heterogeneity.

Our radiomic model was able to predict a GR to induction chemotherapy with an AUC of 0.76 in the training cohort. In the testing cohort, the radiomic model had some predictive ability though this was diminished from the training cohort. Notably, the integration of our radiomic model as a Rad-score with previously available clinical information improved predictive ability in both our training $(\mathrm{AUC}=0.85)$ and testing cohorts $(\mathrm{AUC}=0.75)$. 
This is in line with previous studies which have found similar synergistic improvements between radiomic and clinical-based predictions [20,42]. Recently, Zhai et al. demonstrated and externally validated a combined radiomic-clinical model to predict individual lymph node failure after definitive radiotherapy with a c-index $=0.80$ in the internal validation cohort and c-index $=0.71$ in the externally validated study $[42,43]$. Like our model, their model used a combined radiomic and clinical approach, signifying that there is useful and complementary information that can be extracted from CT imaging of lymph nodes. However, their model requires 3D segmentation of each lymph node, which is significantly more time-consuming than using only one axial slice for feature extraction.

Our study demonstrates that radiomic features of lymph nodes on pretreatment CT imaging can provide useful information in predicting the response to induction chemotherapy. Ideally, prediction of individual nodal response to induction chemotherapy could lead to more personalized radiation dose intensification focusing on high-risk nodes or even direct surgical dissection for high-risk nodes. However, this is only a preliminary study. While we were able to internally validate our model, external multi-center validation is the next step.

\section{Conclusions}

A pretreatment CT-based lymph node radiomic signature combined with clinical parameters is able to predict nodal response to induction chemotherapy for patients with locally advanced HNSCC. Future studies are needed to externally validate this model.

Supplementary Materials: The following are available online at https:/ / www.mdpi.com/2075-441 8/11/4/588/s1, Supplemental S1: radiomic features and descriptions, Table S1: linear regression, Figure S1: LASSO regression optimization.

Author Contributions: Conceptualization, M.H.Z., D.C., D.T.G.; methodology, M.H.Z., D.C., D.T.G.; software, M.H.Z., D.C.; validation, M.H.Z., D.C.; formal analysis, M.H.Z., D.C., D.T.G.; investigation, M.H.Z., D.C.; resources, D.T.G.; data curation, M.H.Z., D.C.; writing-original draft preparation, M.H.Z., D.C.; writing—review and editing, M.H.Z., D.C., D.T.G.; visualization, M.H.Z.; supervision, M.H.Z., D.T.G.; project administration, M.H.Z.; funding acquisition, D.T.G. All authors have read and agreed to the published version of the manuscript.

Funding: The project described was supported by RSNA Research \& Education Foundation, through grant number RMS2002. The content is solely the responsibility of the authors and does not necessarily represent the official views of the RSNA R\&E Foundation.

Institutional Review Board Statement: The study was conducted according to the guidelines of the Declaration of Helsinki, and approved by the Institutional Review Board of The University of Chicago (IRB14-0749, approval date 5/19/2020).

Informed Consent Statement: Individual consent for this anonymized and retrospective study was waived.

Data Availability Statement: The data presented in this study are available on request from the corresponding author.

Conflicts of Interest: The authors declare no conflict of interest.

\section{References}

1. Bray, F.; Ferlay, J.; Soerjomataram, I.; Siegel, R.L.; Torre, L.A.; Jemal, A. Global Cancer Statistics 2018: GLOBOCAN Estimates of Incidence and Mortality Worldwide for 36 Cancers in 185 Countries. CA Cancer J. Clin. 2018, 68, 394-424. [CrossRef] [PubMed]

2. Jemal, A.; Bray, F.; Center, M.M.; Ferlay, J.; Ward, E.; Forman, D. Global Cancer Statistics. CA Cancer J. Clin. 2011, 61, 69-90. [CrossRef] [PubMed]

3. Gatta, G.; Botta, L.; Sánchez, M.J.; Anderson, L.A.; Pierannunzio, D.; Licitra, L. EUROCARE Working Group: Prognoses and Improvement for Head and Neck Cancers Diagnosed in Europe in Early 2000s: The EUROCARE-5 Population-Based Study. Eur. J. Cancer 2015, 51, 2130-2143. [CrossRef]

4. Mermod, M.; Tolstonog, G.; Simon, C.; Monnier, Y. Extracapsular Spread in Head and Neck Squamous Cell Carcinoma: A Systematic Review and Meta-Analysis. Oral Oncol. 2016, 62, 60-71. [CrossRef] [PubMed] 
5. Marur, S.; Forastiere, A.A. Head and Neck Squamous Cell Carcinoma: Update on Epidemiology, Diagnosis, and Treatment. Mayo Clin. Proc. 2016, 91, 386-396. [CrossRef] [PubMed]

6. Puri, S.K.; Fan, C.-Y.; Hanna, E. Significance of Extracapsular Lymph Node Metastases in Patients with Head and Neck Squamous Cell Carcinoma. Curr. Opin. Otolaryngol. Head Neck Surg. 2003, 11, 119-123. [CrossRef]

7. Economopoulou, P.; de Bree, R.; Kotsantis, I.; Psyrri, A. Diagnostic Tumor Markers in Head and Neck Squamous Cell Carcinoma (HNSCC) in the Clinical Setting. Front. Oncol. 2019, 9. [CrossRef]

8. Weinberger, P.M.; Yu, Z.; Haffty, B.G.; Kowalski, D.; Harigopal, M.; Brandsma, J.; Sasaki, C.; Joe, J.; Camp, R.L.; Rimm, D.L.; et al. Molecular Classification Identifies a Subset of Human Papillomavirus-Associated Oropharyngeal Cancers with Favorable Prognosis. J. Clin. Oncol. 2006, 24, 736-747. [CrossRef]

9. Gupta, T.; Master, Z.; Kannan, S.; Agarwal, J.P.; Ghsoh-Laskar, S.; Rangarajan, V.; Murthy, V.; Budrukkar, A. Diagnostic Performance of Post-Treatment FDG PET or FDG PET/CT Imaging in Head and Neck Cancer: A Systematic Review and Meta-Analysis. Eur. J. Nucl. Med. Mol. Imaging 2011, 38, 2083-2095. [CrossRef]

10. Machtay, M.; Natwa, M.; Andrel, J.; Hyslop, T.; Anne, P.R.; Lavarino, J.; Intenzo, C.M.; Keane, W. Pretreatment FDG-PET Standardized Uptake Value as a Prognostic Factor for Outcome in Head and Neck Cancer. Head Neck 2009, 31, 195-201. [CrossRef]

11. Wakabayashi, T.; Ouhmich, F.; Gonzalez-Cabrera, C.; Felli, E.; Saviano, A.; Agnus, V.; Savadjiev, P.; Baumert, T.F.; Pessaux, P.; Marescaux, J.; et al. Radiomics in Hepatocellular Carcinoma: A Quantitative Review. Hepatol. Int. 2019, 13, 546-559. [CrossRef]

12. Valdora, F.; Houssami, N.; Rossi, F.; Calabrese, M.; Tagliafico, A.S. Rapid Review: Radiomics and Breast Cancer. Breast Cancer Res. Treat 2018, 169, 217-229. [CrossRef]

13. Thawani, R.; McLane, M.; Beig, N.; Ghose, S.; Prasanna, P.; Velcheti, V.; Madabhushi, A. Radiomics and Radiogenomics in Lung Cancer: A Review for the Clinician. Lung Cancer 2018, 115, 34-41. [CrossRef]

14. Sun, Y.; Reynolds, H.M.; Parameswaran, B.; Wraith, D.; Finnegan, M.E.; Williams, S.; Haworth, A. Multiparametric MRI and Radiomics in Prostate Cancer: A Review. Australas Phys. Eng. Sci. Med. 2019, 42, 3-25. [CrossRef] [PubMed]

15. Raja, J.V.; Khan, M.; Ramachandra, V.K.; Al-Kadi, O. Texture Analysis of CT Images in the Characterization of Oral Cancers Involving Buccal Mucosa. Dentomaxillofac. Radiol. 2012, 41, 475-480. [CrossRef] [PubMed]

16. Huang, C.; Cintra, M.; Brennan, K.; Zhou, M.; Colevas, A.D.; Fischbein, N.; Zhu, S.; Gevaert, O. Development and Validation of Radiomic Signatures of Head and Neck Squamous Cell Carcinoma Molecular Features and Subtypes. EBioMedicine 2019, 45, 70-80. [CrossRef]

17. Zhu, Y.; Mohamed, A.S.R.; Lai, S.Y.; Yang, S.; Kanwar, A.; Wei, L.; Kamal, M.; Sengupta, S.; Elhalawani, H.; Skinner, H.; et al. Imaging-Genomic Study of Head and Neck Squamous Cell Carcinoma: Associations between Radiomic Phenotypes and Genomic Mechanisms via Integration of The Cancer Genome Atlas and the Cancer Imaging Archive. JCO Clin. Cancer Inform. 2019, 1-9. [CrossRef]

18. Cheng, Z.; Nakatsugawa, M.; Zhou, X.C.; Hu, C.; Greco, S.; Kiess, A.; Page, B.; Alcorn, S.; Haller, J.; Utsunomiya, K.; et al. Utility of a Clinical Decision Support System in Weight Loss Prediction After Head and Neck Cancer Radiotherapy. JCO Clin. Cancer Inform. 2019, 3, 1-11. [CrossRef]

19. Bogowicz, M.; Tanadini-Lang, S.; Veit-Haibach, P.; Pruschy, M.; Bender, S.; Sharma, A.; Hüllner, M.; Studer, G.; Stieb, S.; Hemmatazad, H.; et al. Perfusion CT Radiomics as Potential Prognostic Biomarker in Head and Neck Squamous Cell Carcinoma. Acta Oncol. 2019, 58, 1514-1518. [CrossRef]

20. Zhai, T.-T.; Langendijk, J.A.; van Dijk, L.V.; Halmos, G.B.; Witjes, M.J.H.; Oosting, S.F.; Noordzij, W.; Sijtsema, N.M.; Steenbakkers, R.J.H.M. The Prognostic Value of CT-Based Image-Biomarkers for Head and Neck Cancer Patients Treated with Definitive (Chemo-)Radiation. Oral Oncol. 2019, 95, 178-186. [CrossRef] [PubMed]

21. Liu, Y.; Shi, H.; Huang, S.; Chen, X.; Zhou, H.; Chang, H.; Xia, Y.; Wang, G.; Yang, X. Early Prediction of Acute Xerostomia during Radiation Therapy for Nasopharyngeal Cancer Based on Delta Radiomics from CT Images. Quant. Imaging Med. Surg. 2019, 9, 1288-1302. [CrossRef]

22. Xing, Y.; Zhang, J.; Lin, H.; Gold, K.A.; Sturgis, E.M.; Garden, A.S.; Lee, J.J.; William, W.N. Relationship between Level of Lymph Node Metastasis and Survival in Locally Advanced Head and Neck Squamous Cell Carcinoma. Cancer 2016, 122, 534-545. [CrossRef]

23. Villaflor, V.M.; Melotek, J.M.; Karrison, T.G.; Brisson, R.J.; Blair, E.A.; Portugal, L.; De Souza, J.A.; Ginat, D.T.; Stenson, K.M.; Langerman, A.; et al. Response-Adapted Volume de-Escalation (RAVD) in Locally Advanced Head and Neck Cancer. Ann. Oncol. 2016, 27, 908-913. [CrossRef]

24. Fedorov, A.; Beichel, R.; Kalpathy-Cramer, J.; Finet, J.; Fillion-Robin, J.-C.; Pujol, S.; Bauer, C.; Jennings, D.; Fennessy, F.; Sonka, M.; et al. 3D Slicer as an Image Computing Platform for the Quantitative Imaging Network. Magn. Reson. Imaging 2012, 30, 1323-1341. [CrossRef]

25. Van Griethuysen, J.J.M.; Fedorov, A.; Parmar, C.; Hosny, A.; Aucoin, N.; Narayan, V.; Beets-Tan, R.G.H.; Fillion-Robin, J.-C.; Pieper, S.; Aerts, H.J.W.L. Computational Radiomics System to Decode the Radiographic Phenotype. Cancer Res. 2017, 77, e104-e107. [CrossRef] [PubMed]

26. Zwanenburg, A.; Leger, S.; Vallières, M.; Löck, S. Image Biomarker Standardisation Initiative. Radiology 2020, 295, 328-338. [CrossRef] [PubMed]

27. Buch, K.; Fujita, A.; Li, B.; Kawashima, Y.; Qureshi, M.M.; Sakai, O. Using Texture Analysis to Determine Human Papillomavirus Status of Oropharyngeal Squamous Cell Carcinomas on CT. Am. J. Neuroradiol. 2015, 36, 1343-1348. [CrossRef] 
28. Fujita, A.; Buch, K.; Li, B.; Kawashima, Y.; Qureshi, M.M.; Sakai, O. Difference Between HPV-Positive and HPV-Negative Non-Oropharyngeal Head and Neck Cancer: Texture Analysis Features on CT. J. Comput. Assist. Tomogr. 2016, $40,43-47$. [CrossRef]

29. Kann, B.H.; Aneja, S.; Loganadane, G.V.; Kelly, J.R.; Smith, S.M.; Decker, R.H.; Yu, J.B.; Park, H.S.; Yarbrough, W.G.; Malhotra, A.; et al. Pretreatment Identification of Head and Neck Cancer Nodal Metastasis and Extranodal Extension Using Deep Learning Neural Networks. Sci. Rep. 2018, 8, 14036. [CrossRef]

30. Zwirner, K.; Hilke, F.J.; Demidov, G.; Socarras Fernandez, J.; Ossowski, S.; Gani, C.; Thorwarth, D.; Riess, O.; Zips, D.; Schroeder, C.; et al. Radiogenomics in Head and Neck Cancer: Correlation of Radiomic Heterogeneity and Somatic Mutations in TP53, FAT1 and KMT2D. Strahlenther. Onkol. 2019, 195, 771-779. [CrossRef] [PubMed]

31. Aerts, H.J.W.L.; Velazquez, E.R.; Leijenaar, R.T.H.; Parmar, C.; Grossmann, P.; Carvalho, S.; Cavalho, S.; Bussink, J.; Monshouwer, R.; Haibe-Kains, B.; et al. Decoding Tumour Phenotype by Noninvasive Imaging Using a Quantitative Radiomics Approach. Nat. Commun. 2014, 5, 4006. [CrossRef] [PubMed]

32. Brierley, J.D.; Gospodarowicz, M.K.; Wittekind, C. TNM Classification of Malignant Tumours; John Wiley \& Sons: Hoboken, NJ, USA, 2017; ISBN 978-1-119-26357-9.

33. Mascitti, M.; Rubini, C.; De Michele, F.; Balercia, P.; Girotto, R.; Troiano, G.; Lo Muzio, L.; Santarelli, A. American Joint Committee on Cancer Staging System 7th Edition versus 8th Edition: Any Improvement for Patients with Squamous Cell Carcinoma of the Tongue? Oral Surg. Oral Med. Oral Pathol. Oral Radiol. 2018, 126, 415-423. [CrossRef]

34. Majercakova, K.; Valero, C.; López, M.; García, J.; Farré, N.; Quer, M.; León, X. Postoperative Staging of the Neck Dissection Using Extracapsular Spread and Lymph Node Ratio as Prognostic Factors in HPV-Negative Head and Neck Squamous Cell Carcinoma Patients. Oral Oncol. 2018, 77, 37-42. [CrossRef]

35. León, X.; Neumann, E.; Gutiérrez, A.; García, J.; López, M.; Quer, M. Weighted Lymph Node Ratio: New Tool in the Assessment of Postoperative Staging of the Neck Dissection in HPV-Negative Head and Neck Squamous Cell Carcinoma Patients. Head Neck 2020, 42, 2912-2919. [CrossRef] [PubMed]

36. Veres, D.S.; Máthé, D.; Hegedûs, N.; Horváth, I.; Kiss, F.J.; Taba, G.; Tóth-Bodrogi, E.; Kovács, T.; Szigeti, K. Radiomic Detection of Microscopic Tumorous Lesions in Small Animal Liver SPECT Imaging. Ejnmmi Res. 2019, 9, 67. [CrossRef] [PubMed]

37. Ganeshan, B.; Miles, K.A. Quantifying Tumour Heterogeneity with CT. Cancer Imaging 2013, 13, 140-149. [CrossRef]

38. Yun, G.; Kim, Y.H.; Lee, Y.J.; Kim, B.; Hwang, J.-H.; Choi, D.J. Tumor Heterogeneity of Pancreas Head Cancer Assessed by CT Texture Analysis: Association with Survival Outcomes after Curative Resection. Sci. Rep. 2018, 8, 7226. [CrossRef]

39. Chen, C.-H.; Chang, C.-K.; Tu, C.-Y.; Liao, W.-C.; Wu, B.-R.; Chou, K.-T.; Chiou, Y.-R.; Yang, S.-N.; Zhang, G.; Huang, T.-C. Radiomic Features Analysis in Computed Tomography Images of Lung Nodule Classification. PLoS ONE 2018, 13, e0192002. [CrossRef]

40. Yachida, S.; Jones, S.; Bozic, I.; Antal, T.; Leary, R.; Fu, B.; Kamiyama, M.; Hruban, R.H.; Eshleman, J.R.; Nowak, M.A.; et al. Distant Metastasis Occurs Late during the Genetic Evolution of Pancreatic Cancer. Nature 2010, 467, 1114-1117. [CrossRef]

41. Gerlinger, M.; Rowan, A.J.; Horswell, S.; Larkin, J.; Endesfelder, D.; Gronroos, E.; Martinez, P.; Matthews, N.; Stewart, A.; Tarpey, P.; et al. Intratumor Heterogeneity and Branched Evolution Revealed by Multiregion Sequencing. N. Engl. J. Med. 2012, 366, 883-892. [CrossRef]

42. Zhai, T.-T.; Langendijk, J.A.; van Dijk, L.V.; van der Schaaf, A.; Sommers, L.; Vemer-van den Hoek, J.G.M.; Bijl, H.P.; Halmos, G.B.; Witjes, M.J.H.; Oosting, S.F.; et al. Pre-Treatment Radiomic Features Predict Individual Lymph Node Failure for Head and Neck Cancer Patients. Radiother. Oncol. 2020, 146, 58-65. [CrossRef] [PubMed]

43. Zhai, T.-T.; Wesseling, F.; Langendijk, J.A.; Shi, Z.; Kalendralis, P.; van Dijk, L.V.; Hoebers, F.; Steenbakkers, R.J.H.M.; Dekker, A.; Wee, L.; et al. External Validation of Nodal Failure Prediction Models Including Radiomics in Head and Neck Cancer. Oral Oncol. 2021, 112, 105083. [CrossRef] [PubMed] 